\title{
EL DESARROLLO DEL TURISMO MARINERO EN ESPAÑA: DIFERENCIAS REGIONALES
}

\author{
Daniel Moreno Muñoz* \\ Universidad de Murcia \\ https://orcid.org/0000-0003-2264-263X
}

\section{RESUMEN}

En España desde comienzos de este siglo se están desarrollando iniciativas turísticas relacionadas con la actividad pesquera. Se pretende poner en valor para el aprovechamiento turístico la cultura de la pesca y el trabajo de los pescadores, con el fin de generar nuevas rentas que beneficien al sector pesquero y también contribuyan al desarrollo económico local de los puertos en los que se da esta actividad. Este artículo tiene como objetivos fundamentales: la recopilación de la normativa legal que ampara a esta actividad, tanto a nivel autonómico como estatal, y la relación de las iniciativas que se ofertan en cada Comunidad Autónoma para señalar sus singularidades y los contrastes entre las mismas.

Palabras clave: turismo marinero; sector pesquero; turismo sostenible.

\section{The development of marine tourism in Spain: Regional differences}

\begin{abstract}
In Spain, since the beginning of this century, tourism initiatives related to fishing activity have been developed. It is intended to value the culture of fishing and the work of fishermen for tourist use, in order to generate new income that benefits the fishing sector and also contributes to the local economic development of the port in which this activity occurs. This article has as fundamental objectives: the compilation of the legal regulations that protect this activity, both at the regional state level, and the relationship of the initiatives that are offered in each Autonomous Community to point out their singularities and the contrasts between them.
\end{abstract}

Key words: marine tourism; fishing sector; sustainable tourism.

Fecha de recepción: 8 de enero de 2020 .

Fecha de aceptación: 5 de junio de 2020.

*Grupo de Investigación "Dinámicas Territoriales: Análisis y Ordenación”. Departamento de Geografía. Universidad de Murcia. Campus de La Merced. 30001 MURCIA (España). E-mail: daniel.moreno1@um.es 


\section{INTRODUCCIÓN}

En España la pesca es una actividad histórica, rica en tradiciones, que juega un importante papel desde el punto de vista económico y sociocultural. Desde tiempos inmemoriales, el sector pesquero ha sido una de las principales fuentes de riqueza de las localidades costeras españolas. Sin embargo, en las últimas décadas, como consecuencia del intenso desarrollo del turismo en los espacios litorales, esta actividad ha quedado relegada a un segundo plano.

La oferta turística en España se ha cimentado en torno a la modalidad de sol y playa (García y Albuquerque, 2003), especialmente en la fachada mediterránea, donde se han construido numerosos hoteles, apartamentos y pensiones pero, sobre todo, miles de viviendas que son adquiridas para segundas residencias (Huete, 2008). Es decir, se da preferentemente un turismo de masas (Coll y Seguí, 2014) con una acusada estacionalidad estival.

Buena parte de los destinos españoles de sol y playa, siguiendo la teoría del ciclo de la vida de los destinos turísticos de Butler (1980), se encuentran en fase de estancamiento e incluso de declive, debido fundamentalmente por la pérdida de atractivo y las nuevas motivaciones (Heitmann, 2011). Por ello, en los últimos años, existe una importante tendencia para diversificar la oferta (Ivars et al., 2013; Benur y Bramwell, 2015), con el impulso de productos novedosos mediante planes para la renovación del destino, una posible reorientación del modelo y la redefinición de la imagen de la marca (Vera y Baños, 2016). Se pretende conseguir una mayor competitividad a través productos de calidad que consigan atraer nuevos turistas. Es decir, no se busca tanto la cantidad sino la distinción, incorporando elementos relacionados con el paisaje o la identidad local (González y Anton, 2016).

La actividad pesquera constituye uno de los sectores económicos tradicionales en España, y se desarrolla en todas las Comunidades Autónomas españolas con litoral (Rose1ló, 1986; Salvà, 1987; Molinero, 1993; Lois, 2001). Si bien el número de embarcaciones, y por tanto el de empleos en el sector, no se reparte de una manera homogénea, todas ellas guardan una semejanza común, como es el predominio de la pesca costera o litoral mediante la flota de bajura (Moreno, 2018). Actualmente, España es el primer productor de pesca de la Unión Europea, según datos del Informe del Sector Pesquero Español (2019). Sin embargo, se ha producido una tendencia regresiva en las últimas décadas respecto tanto en el número de barcos como de trabajadores empleados, derivado de factores sociales, políticos, económicos y biológicos. Es decir, las comunidades de pescadores se enfrentan a nuevos retos como consecuencia de este declive (Miret-Pastor et al., 2018), por lo que se busca la dinamización de la actividad y con ello nuevas rentas complementarias que permitan mejorar la situación (Gràcia, 2016).

El turismo marinero lleva unos años fomentadose en distintas zonas costeras del mundo (Kauppila y Karjalainen, 2012; Pérez y Espejo, 2012), especialmente en los países más turísticos, como es el caso de España (Miret-Pastor et al., 2020). Es decir, se busca unir la actividad pesquera y la turística. Este hecho, de acuerdo con Martínez y Moreno (2014), viene motivado por la compleja situación que vive el sector pesquero tradicional, sumido en una crisis debido, entre otros factores, a la falta de trabajadores dispuestos para faenar en la mar, la retirada de las embarcaciones y la dureza del oficio, y por tanto a la búsqueda de nuevas singularidades competitivas para atraer a un mayor número de turistas. Conviene mencionar que esta modalidad turística engloba actividades en los puertos 
pesqueros (degustaciones gastronómicas, visitas a las lonjas y a las instalaciones portuarias (Figura 1), talleres de nudos o rutas guiadas por elementos patrimoniales que tienen relación directa o indirecta con la pesca) y en el mar (visualización in situ de la jornada de pesca), lo que se conoce como pesca-turismo (Moreno, 2018). Por ende, tal y como afirman Herrera-Racionero et al., (2018), se trata de propuestas novedosas que responden a la necesidad de diversificación de la actividad pesquera y turística. No obstante, tal y como indican Caamaño et al., (2021) no se puede afirmar que el turismo marinero sea una vía complementaria de ingresos para el sector pesquero dado que, mayoritariamente, las empresas implicadas son turísticas. Sin embargo, la labor que realizan de cara a la puesta en valor de la cultura marítima es indudable y de este modo se está favoreciendo la conservación y promoción de la pesca y toda su cultura.

\section{Figura 1 \\ PESCADORES REMENDANDO REDES EN PUERTO DE MAZARRÓN. REGIÓN DE MURCIA}

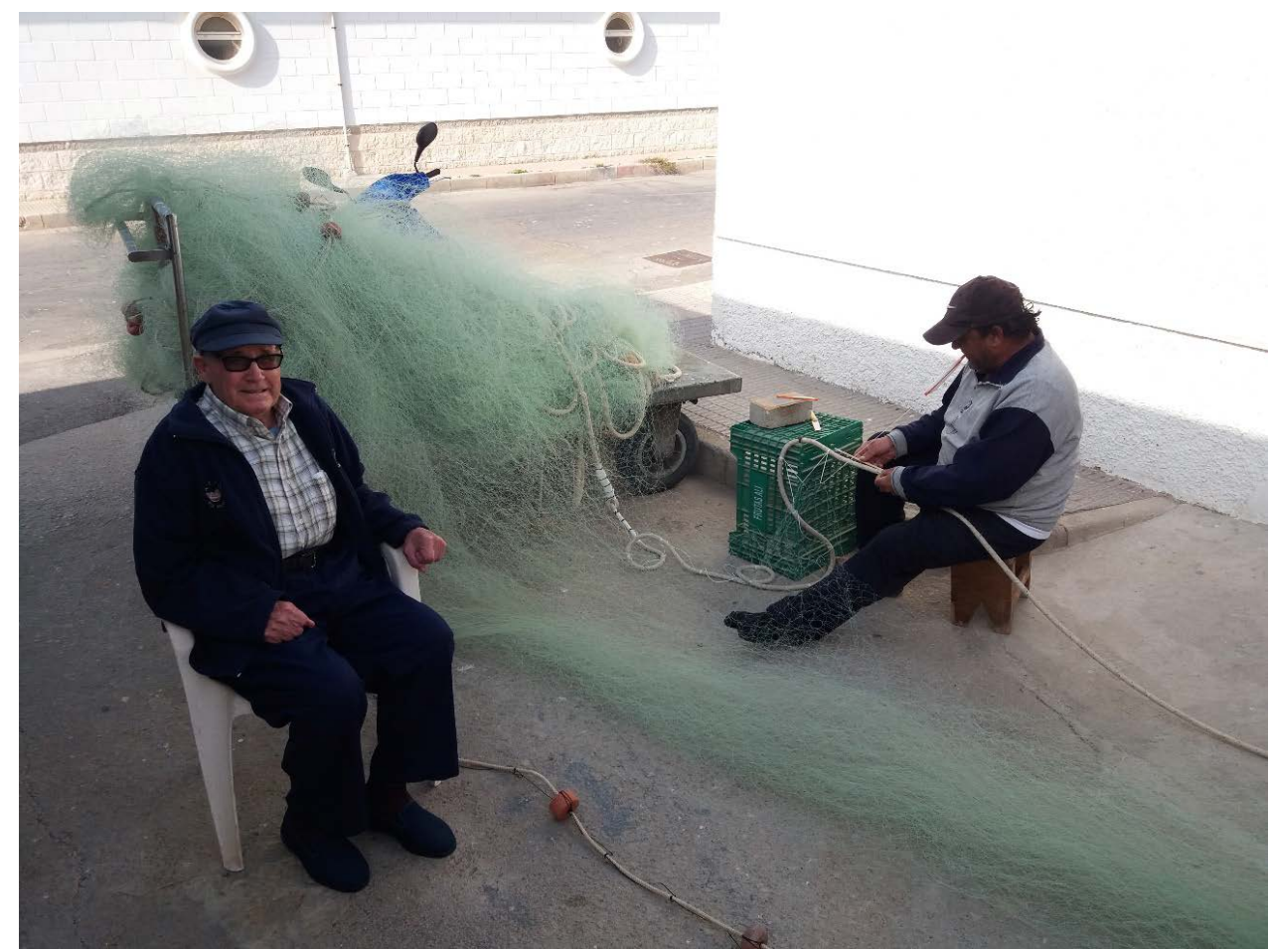

Fuente: Autor.

De acuerdo con Jiménez (2016), las poblaciones costeras pueden ser consideradas como "pesqueras", ya que viven con una identidad diferenciada por el hecho de que gran parte de sus elementos culturales tienen una influencia marinera. En este sentido, el pilar básico 
sobre el que se desarrolla el turismo marinero es el patrimonio cultural pesquero, tangible e intangible, que puede ser aprovechado como un recurso turístico (Moreno, 2018). Es decir, en estos territorios existe un auténtico muestrario de tradiciones vivas dignas de conocer de primera mano. Esta modalidad turística persigue diversos objetivos: i) Obtención por parte de los armadores de las embarcaciones de nuevos ingresos económicos; ii) Conseguir un beneficio socioeconómico para los lugares donde se desarrolle; y iii) Valorizar y dar a conocer todo lo que concierne a la cultura marítima de las poblaciones costeras.

En España el turismo marinero lleva impulsándose algo más de una década a través de las Cofradías de Pescadores, empresas privadas, ayuntamientos y GALP (Grupos de Acción Local Pesqueros). Es decir, ha vivido un corto recorrido (Pardellas y Espejo, 2013), por lo que se puede considerar como una actividad novedosa (Miret-Pastor et al., 2015). No obstante, parece existir una clara predisposición de todas ellas para que esta modalidad turística se convierta en un nuevo producto que complemente al modelo tradicional de sol y playa, con ello se consigan nuevas singularidades competitivas.

\section{MARCO TEÓRICO}

El análisis del turismo marinero surge con la implantación de esta modalidad turística en el panorama internacional a comienzos del siglo XX. Al ser una actividad reciente, los estudios en la literatura especializada no son abundantes. No obstante, en los últimos años se han generado publicaciones que se están convirtiendo en modelos de referencia (Moreno et al., 2016).

La primera alusión de forma indirecta al turismo pesquero la realiza Hall (2001), advirtiendo que los destinos tradicionales de sol y playa podrían diversificar su oferta desarrollando actividades turísticas en el mar, como la observación directa del trabajo de los pescadores.

Los primeros estudios sobre esta modalidad turística se publicaron en el año 2003. Cheong (2003) analiza cómo los pescadores de Corea del Sur trasladan a los turistas a contemplar la faena pesquera y los alojan en sus viviendas para conseguir mayores beneficios económicos. Por otro lado, Woods-Ballard et al. (2003) tratan sobre la oferta turística del avistamiento de ballenas en los mares del norte de Escocia durante el paro biológico, con el objetivo de conseguir unos rendimientos económicos adicionales a la pesca en esos momentos de inactividad. Por su parte, Pascual y Santana (2003), en el primer trabajo sobre el turismo marinero publicado en España, muestran la crisis de la pesca artesanal en las Islas Canarias motivada, entre otros factores, por el cambio del uso en los espacios costeros. Por esta razón, reflexionan sobre la posibilidad de aunar pesca y turismo.

Con las medidas de la Unión Europea para diversificar el sector pesquero mediante proyectos que ponen en valor la pesca como recurso turístico, surgen investigaciones acerca de los mismos y de las acciones llevadas a cabo en los territorios acogidos a estas iniciativas y en otros que también han impulsado el turismo marinero (Miret-Pastor et al., 2019). España se acogió a varios de estas iniciativas (PRESPO, SAGITAL o MARIMED), que han objeto de diversos estudios. Pardellas et al., (2011), consideran que existen diferencias entre las regiones de los distintos estados de la Unión Europea a la hora de impulsar el turismo marinero. Por ejemplo, en España, se ha desarrollado de forma más 
intensa en la costa Atlántica que en las marinerías del Mediterráneo. Estas disimilitudes han sido abordadas en diversos estudios de caso, uno de ellos a escala regional (Ballesteros et al., 2012) y otros más localistas (Padín y Aboy, 2010; De la Cruz et al., 2012; Pérez y Espejo, 2012; Martínez y Moreno, 2013). Por su parte en Italia, Cillari et al. (2012) hacen referencia a Sicilia como la única zona del país transalpino donde se pone en valor como recurso turístico un arte de pesca tradicional en vías de desaparición, el palangre de fondo, que genera unos beneficios adicionales durante el estío a los pescadores mediante demostraciones a bordo sus embarcaciones.

La percepción de los pescadores es uno de los factores más decisivos a la hora de impulsar la pesca-turismo. Existe una clara predisposición en Carnaubal (Brasil), en la Comunidad Valenciana (España), Taiwan y en las Islas Galápagos (Ecuador) (Schuhbauer y Koch, 2013; Vasconcelos et al., 2014; Chen y Chang, 2017; Herrera-Racionero et al., 2018), debido, como no puede ser de otro modo, a la posibilidad de conseguir nuevas rentas económicas a través del turismo. Sin embargo, en otros lugares como Filipinas o Zanzíbar, los armadores se muestran contrarios a desarrollar esta actividad porque consideran al turismo como un invasor de su lugar de trabajo (Porter y Orams, 2014; Sebit et al., 2016).

Como se ha mencionado anteriormente, el patrimonio material e inmaterial ligado a la pesca es esencial para la puesta en marcha del turismo marinero. Así, las degustaciones gastronómicas de productos del mar se han convertido en una de las iniciativas más demandadas por los turistas (Alegret, 2013; Carbonell 2014). Por ejemplo en Istria (Eslovenia) la población local estima que esta forma de identidad territorial puede convertirse en un recurso y una nueva oportunidad de desarrollo (Rogelja y Janko, 2017). Además, otros elementos que conforman el paisaje del litoral, como torres de vigilancia costera, faros, lonjas o espacios museísticos dedicados a la pesca, se han incluido en la oferta turística de estos territorios (Tuddenham, 2010). Es decir, se han puesto en valor los numerosos recursos de las comunidades pesqueras (Patiño, 2016; Lois y Piñeiro, 2020).

Por último, es necesario destacar un estudio sobre el papel de la mujer en el turismo marinero. En este sentido, Caamaño et al., (2020), muestran como en Galicia existen diversos proyectos de esta modalidad que son liderados por mujeres. No obstante, se pone de relieve la necesidad de promover aún más la iniciativa femenina en este ámbito turístico.

\section{OBJETIVOS Y METODOLOGÍA}

Dado que el turismo marinero se ha convertido en una oportunidad de desarrollo para las localidades litorales con tradición marítima, surge el planteamiento de abordar una investigación en la que se indague en la situación actual de esta modalidad turística en España. El objetivo fundamental que guía este estudio es difundir los contrastes existentes entre las Comunidades Autónomas. Para ello, es necesario analizar los marcos legislativos vigentes, tanto a nivel nacional como autonómico en materia pesquera , así como relacionar las iniciativas más relevantes de turismo marinero ofertadas en cada una de las regiones españolas.

Para la elaboración de esta investigación se ha llevado a cabo, en primer lugar, una revisión bibliográfica exhaustiva acerca del turismo marinero, con el fin de confeccionar una introducción y un marco teórico adecuados. Seguidamente, se ha procedido al estudio de las leyes nacionales y autonómicas vigentes en materia de pesca para conocer lo esencial de las 
mismas y, por último, se han recopilado a través de diversos medios (literatura especializada, páginas webs de la administración pública y de operadores turísticos, así como a través de visitas personales) para conocer la oferta de este tipo de producto turístico tan singular y especializado que se da en cada una de las Comunidades Autónomas de España.

\section{EL TURISMO MARINERO EN LA LEGISLACIÓN ESPAÑOLA}

El impulso del turismo marinero en España en la última década ha supuesto cambios sustanciales en la legislación pesquera. Este hecho viene dado especialmente por una de las actividades que engloba esta modalidad turística, la pesca-turismo. Para su correcto desarrollo es necesario un marco legal adecuado a las circunstancias, por lo que algunas Comunidades Autónomas Españolas han modificado sus leyes de pesca, con el fin de conseguir una diversificación del sector y realizar bajo las mejores condiciones posibles la pesca-turismo.

En este apartado de la investigación se abordan en primer lugar las leyes de pesca autonómicas, debido a que algunas Comunidades Autónomas incluyeron apartados referidos a la pesca-turismo y al turismo marinero antes que la legislación estatal. En este sentido, tanto las leyes autonómicas como la nacional presentan matices que conviene señalar.

\subsection{Galicia}

Galicia ha sido la primera Comunidad Autónoma española en incorporar a su legislación la posibilidad de desarrollar el turismo marinero. La Ley 6/2009, de 11 de diciembre, de modificación de la Ley 11/2008, de 3 de diciembre, de Pesca de Galicia, incluye una serie de actividades englobadas dentro de esta modalidad turística (pesca-turismo, rutas guiadas por profesionales del mar y degustaciones gastronómicas para valorizar los productos pesqueros).

En lo que respecta a la pesca-turismo, la legislación gallega no especifica las condiciones que deben tener las embarcaciones para llevar a cabo estas actividades, seguros de responsabilidad civil, personas autorizadas o capacidad de pasajeros por eslora de la embarcación. Es decir, existe un vacío legal para estos aspectos.

Por otro lado, esta Ley, solo concreta a "profesionales del mar" como personas que puedan desarrollar la actividad, entendiéndose éstas como las dedicadas a la pesca, marisqueo o acuicultura. No obstante, antes de poner en marcha cualquier tipo de actividad relacionada con el turismo pesquero, se requiere un informe favorable de la Consellería de Turismo que apruebe su viabilidad.

\subsection{Cataluña}

En 2012 se aprueba el Decreto 87/2012, de 31 de julio, sobre la Pesca-Turismo, el Turismo Pesquero y Acuícola y las demostraciones de pesca en aguas marítimas y continentales de Cataluña. Su objeto es regular, como actividades complementarias del sector pesquero, las actividades vinculadas total o parcialmente con la pesca marítima y la acuicultura, con el fin de que permitan mejorar o complementar las rentas de las 
personas que integran el sector pesquero, y de este modo lograr la diversificación económica del sector y la promoción de sus productos.

Este Decreto incorpora novedades en lo que respecta al desarrollo del turismo marinero. En primer lugar se introduce la figura del "Centro de Turismo Pesquero y Acuícola", considerada como una entidad que gestiona de manera conjunta las actividades de pescaturismo y turismo pesquero y acuícola que se desarrollan en un determinado entorno. Además, según se recoge en el Decreto, es obligatorio, para las personas y los centros que realicen esta modalidad turística, presentar una memoria anual que contenga entre otros aspectos: i) actividades desarrolladas y número de participantes; ii) impacto económico; iii) beneficio socioeconómico para el sector; y iv) material de promoción empleado.

La innovación más importante de este Decreto es la introducción de las condiciones de cobertura de responsabilidad civil. Las personas o entidades dedicadas al turismo pesquero deben tener una póliza de seguros de accidentes personales para los usuarios que practiquen las actividades mencionadas.

\subsection{Islas Baleares}

La cobertura legislativa para la realización del turismo marinero en las Islas Baleares data de 2016, con la aprobación del Decreto 22/2016, de 22 de abril, por el que se regulan las medidas para la diversificación de los sectores pesquero y acuícola en las Islas Baleares.

La principal novedad en materia de turismo pesquero de este Decreto es la incorporación del apartado que recoge las condiciones de seguridad y habitabilidad que deben cumplir las embarcaciones para poder desarrollar correctamente la pesca-turismo. Entre estas condiciones destacan las siguientes:

- Contar con el número y el tipo suficiente de elementos de salvamento y seguridad para todas las personas que embarquen.

- El patrón de la embarcación se responsabilizará de las condiciones de seguridad en las que se embarcan los pasajeros. No se admitirá el embarque de menores sin la autorización por escrito de los padres o tutores o personas que requieran asistencia especial en condiciones que no sean compatibles con la práctica segura de la actividad.

- Los artes de pesca y los elementos auxiliares se manejarán siempre teniendo en cuenta la presencia a bordo de pasajeros no familiarizados con la actividad pesquera.

- El patrón de la embarcación se responsabilizará de que, tanto las condiciones meteorológicas como las operativas del barco, sean adecuadas para el desarrollo de la actividad.

- Los pasajeros, en todo momento, deberán vestir el chaleco salvavidas y disponer del resto de elementos de seguridad necesarios para el tipo de actividad.

Además, Islas Baleares es la única Comunidad Autónoma que fija el número de pasajeros que puede transportar un barco según su eslora. Esto queda estipulado del siguiente modo:

- Para embarcaciones de hasta 8 metros de eslora: dos personas.

- Para embarcaciones de más de 8 y menos de 12 metros de eslora: cuatro personas. 
- Para embarcaciones de más de 12 metros de eslora: ocho personas.

\subsection{Comunidad Valenciana}

En lo que respecta a la Comunidad Valenciana, con la entrada en vigor en 2017 de la Ley 5/2017, de 10 de febrero, de pesca marítima y acuicultura de la Comunitat Valenciana, se crea un marco legal para el turismo pesquero en esta Comunidad Autónoma. Tal y como establece el apartado V del Preámbulo, la sostenibilidad de la actividad pesquera y acuícola requiere, a través de la diversificación, de nuevas fórmulas de negocio diferentes a las tradicionales. Así, la Consellería competente en materia de pesca debe fomentar iniciativas de diversificación que sean un complemento a la actividad pesquera y acuícola. En este caso, el turismo marinero se presenta como la primera línea de diversificación, con el fin de revitalizar zonas costeras donde se desarrolla la actividad, promoviendo, directa o indirectamente, la difusión, la valoración y la promoción de los distintos oficios y modos de vida, así como el patrimonio y la cultura pesquera.

En el Artículo 18 del capítulo III de esta disposición legal se recogen las condiciones específicas necesarias para la realización del turismo pesquero. Son las siguientes:

- Para el ejercicio de la pesca-turismo se deberá contar con las correspondientes autorizaciones administrativas expedidas por la autoridad competente de la Comunidad Valenciana, previa comunicación al Ministerio competente en materia de pesca y obtención de los informes preceptivos de órganos de otras administraciones según normativa vigente.

- La realización de esta actividad será compatible con la pesca extractiva para la que el buque esté autorizado, siempre y cuando dichos barcos reúnan las condiciones de seguridad y habitabilidad que reglamentariamente se establezcan. En todo caso, los turistas embarcados a bordo de estas embarcaciones no podrán ejercer la actividad pesquera. Reglamentariamente se establecerán las condiciones de complementariedad y compatibilidad de la actividad de pesca extractiva y pesca-turismo y las condiciones del embarque del pasaje.

\subsection{España}

Con la aprobación de la Ley 33/2014 por la que se modifica la Ley 3/2001 de Pesca Marítima del Estado, aparecen por primera vez los términos turismo marinero o pesquero y pesca-turismo. La citada Ley contempla un capítulo dedicado a "Medidas de diversificación pesquera y acuícola", estableciendo en Artículo 74 bis lo siguiente: "El Ministerio de Agricultura, Alimentación y Medio Ambiente potenciará las medidas de diversificación económica del sector pesquero y acuícola, en particular, el turismo acuícola, el turismo pesquero o marinero, y la pesca-turismo, sin perjuicio de las competencias del Ministerio de Industria, Energía y Turismo, y de las Comunidades Autónomas.

El mes de abril de 2019 es decisivo para el impulso de la actividad pesca-turismo.A comienzos del mismo el Consejo de Ministros aprueba el Real Decreto239/2019, de 5 de abril, por el que se establecen las condiciones para el desarrollo de la actividad de pesca- 
turismo. Esta disposición, cuya entrada en vigor tiene lugar el día 15 de mayo de 2019 se realiza al amparo del Reglamento (UE) N. ${ }^{\circ} 1380 / 2013$ del Parlamento Europeo y del Consejo, de 11 de diciembre de 2013 sobre la Política Pesquera Común, que tiene entre sus objetivos garantizar que las actividades de la pesca y la acuicultura contribuyan a la sostenibilidad medioambiental, económica y social a largo plazo.

El Real Decreto tiene por objeto regular las condiciones básicas para el desarrollo de la actividad de pesa-turismo respecto a la actividad extractiva ejercida a bordo de buques pesqueros. En su artículo 3 trata el régimen jurídico que afecta a los turistas. Así, éstos no podrán ejercer la actividad pesquera y deberán cumplir los requisitos de seguridad marcados por el Real Decreto.

Para ejercer la pesca-turismo los barcos deben obtener, tal y como se constata en el Artículo 4, un informe favorable del Ministerio de Fomento relativo a las condiciones de seguridad marítimas. Las capitanías marítimas, correspondientes al lugar donde radique el puerto base de la embarcación, comunicarán los informes favorables a la Secretaría General de Pesca del Ministerio de Agricultura, Pesca y Alimentación. La obtención de un informe positivo habilitará al buque a ejercer la pesca-turismo en los caladeros nacionales donde pueda faenar.

En este sentido, el Artículo 6 muestra las condiciones específicas de seguridad y habitabilidad para desarrollar la pesca-turismo. Destacan las siguientes:

- Los barcos deben tener una accesibilidad segura para los turistas, incluidos los que presenten cualquier tipo de discapacidad.

- Las embarcaciones tendrán elementos de salvamento y seguridad suficientes para todas las personas que embarquen. Además, los turistas deberán llevar puesto un chaleco salvavidas de inflado automático para prevenir cualquier caída al mar.

- Los buques tendrán que habilitar espacios a bordo en los que los turistas se encuentren fuera de peligro y no podrán acceder a determinadas zonas del buque cuando se realicen maniobras que puedan entrañar riesgo.

Este Artículo también recoge el número máximo de turistas en función de la eslora de la embarcación, quedando acotado del siguiente modo: i) Los buques que tengan una eslora inferior a 8 metros: como máximo 2 turistas; ii) Los comprendidos entre los 8 y los 12 metros: 4 turistas; iii) Los que cuentan con eslora entre 12 y 20 metros: 8 turistas; y iv) Las embarcaciones superiores a los 20 metros: 12 turistas.

Por tanto, hasta abril de 2019 la pesca-turismo tan solo podía ofertarse en las 4 Comunidades Autónomas con una legislación acorde para ello: Galicia, Cataluña, Islas Baleares y Comunidad Valenciana. Sin embargo, la aprobación del Real Decreto a nivel nacional logra solventar una de las demandas del sector, como es la posibilidad de ofertar la pescaturismo, enmarcada dentro de los objetivos de la Política Pesquera Común de la Unión Europea. Con ello se pretende que la pesca y la acuicultura favorezcan la sostenibilidad medioambiental y socioeconómica a largo plazo, a través de iniciativas diversificatorias que ayuden a mejorar las rentas económicas de los pescadores y la población local, así como la promoción y valorización de su trabajo. 


\section{LA IMPLANTACIÓN DEL TURISMO MARINERO EN LAS COMUNIDADES AUTÓNOMAS ESPAÑOLAS}

El turismo marinero engloba actividades muy diversas relacionadas con el mundo de la pesca. Por ello, se ha realizado un análisis sintetizado de esta modalidad turística en cada una de las Comunidades Autónomas españolas donde se oferta.

\subsection{Galicia}

Galicia es la Comunidad Autónoma española en la que más se ha desarrollado el turismo marinero, hasta el punto que se ha convertido en un producto diferenciador de la oferta turística. En el año 2004, la Cofradía de Pescadores de Lira (Carnota-A Coruña) desarrolla el proyecto Mar de Lira, que abarca actividades de turismo pesquero, cultural y gastronómico, y que tiene por objetivo dinamizar el ámbito socioeconómico de Lira y dar a conocer el mundo de la pesca al resto de la sociedad. También en 2004 surge en Cambados (Pontevedra) la asociación GUIMATUR, con el fin de poner en valor la herencia cultural marítima y revalorizar el papel de la mujer en la actividad pesquera (Patiño, 2016). En este caso, una de las acciones más relevantes es la ruta del marisqueo y la asistencia a la subasta del pescado para centros escolares, con el fin de que los estudiantes conozcan de primera mano el oficio de las mariscadoras gallegas, y la comercialización de los productos pesqueros. En 2005 surge la iniciativa PESCANATUR, integrada por las Cofradías de Pescadores de San Martiño de O Grove, San Telmo de Pontevedra y San Xosé de Cangas, todas en la provincia de Pontevedra. En este caso se ofertan rutas en el mar y en la playa (actividades de pesca-turismo y marisqueo), abarcando también actividades de degustación gastronómica en restaurantes asociados (Pardellas et al., 2011).

Los museos son pieza clave en la promoción de la cultura marítima en Galicia. En ellos se muestra la historia de la pesca, las artes tradicionales, la carpintería de ribera, los naufragios acaecidos en la costa gallega derivados de peligrosidad para la navegación y se exponen objetos relacionados con los pescadores, así como testimonios documentales que permiten conocer de primera mano el oficio del pescador y cómo ha evolucionado. Destacan los museos de Porto do Son (Figura 2), Fisterra, Noia, Rianxo y Laxe (A Coruña), Vigo y A Guarda (Pontevedra) y en San Cibrao (Lugo).

Una de las iniciativas más importantes es MARGALAICA Turismo Mariñeiro. En ella se vinculan 7 Grupos de Acción Costeira gallegos (A Mariña-Ortegal, Golfo Ártabro, Costa da Morte, Seo de Fisterra-Ría de Muros y Noia, Ría de Arousa, Ría de Pontevedra y Ría de Vigo-A Guarda). A través de una página web se accede a ofertas de actividades a bordo de embarcaciones, itinerarios por la costa, alojamientos en casas rurales, museos de la pesca y gastronomía tradicional. Este proyecto cuenta con el apoyo de la Xunta de Galicia, el Ministerio de Medio Ambiente y Medio Rural y Marino, y la Unión Europea a través de su Fondo Social de Pesca. Dentro del proyecto MARGALAICA destaca Come $o$ Mar, que se vertebra a través de la rica y variada gastronomía de la costa gallega y se sustenta en la tradición, cultura y ocio vinculado al mar y a la pesca. Más de 200 bares y restaurantes están adheridos a esta iniciativa, con el fin de atraer nuevos clientes mediante el turismo y, por consiguiente, nuevas rentas. 


\section{Figura 2 \\ DETALLE DE ARTE DE PESCA EN EL MUSEO DA MEMORIA MARIÑEIRA. PORTO DO SON. GALICIA}

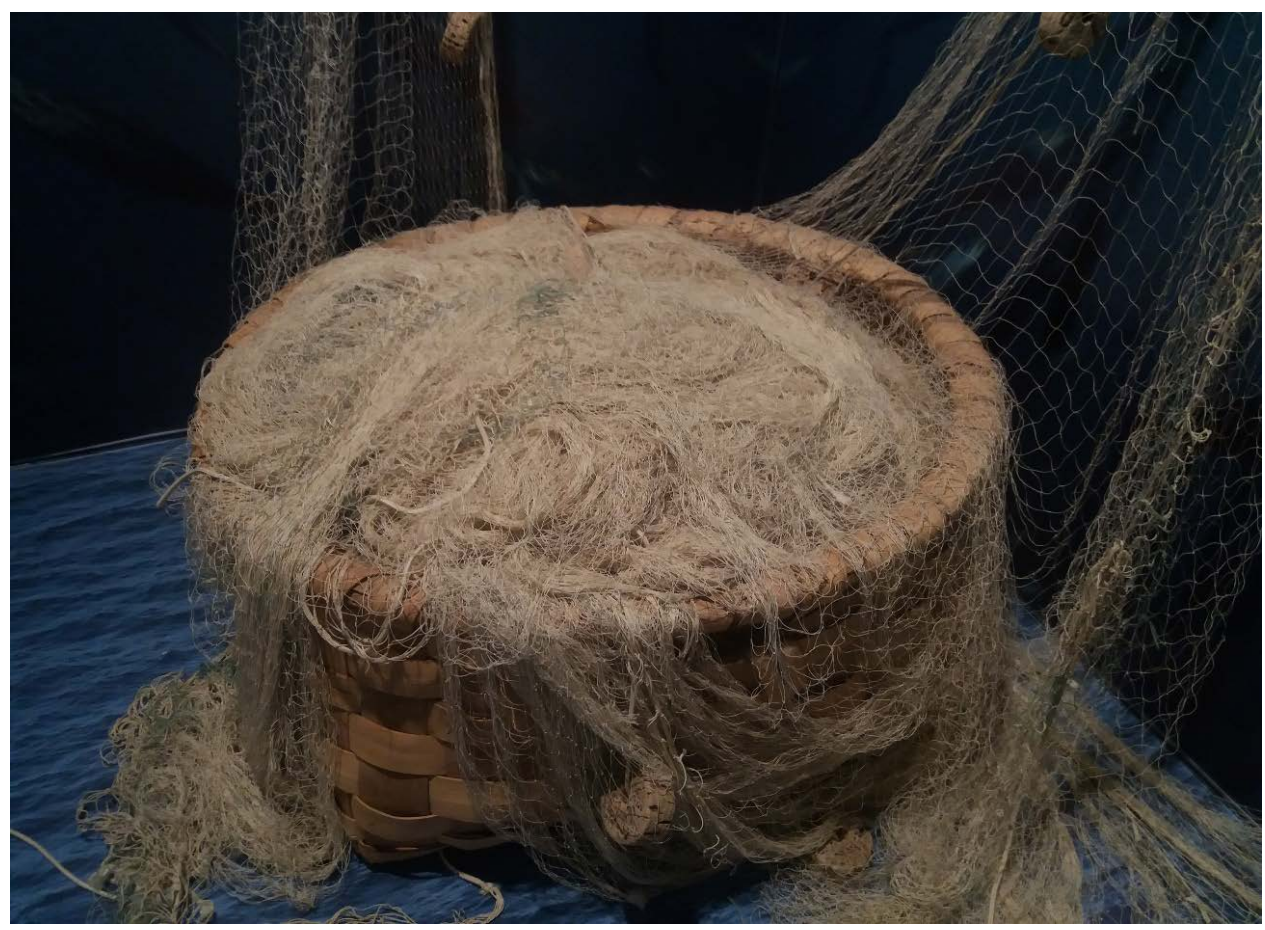

Fuente: Autor.

En una de las ciudades más importantes de Galicia, Vigo, también se ha consolidado el turismo marinero mediante la oferta de visitas guiadas, destacando la de las bateas (estructuras para el cultivo de bivalvos propias de las rías gallegas) que se complementa con un paseo por el centro de Vigo, donde se realiza una degustación gastronómica. También se pueden realizar itinerarios turísticos por los barrios marineros de la ciudad, el paseo marítimo y el mercado de O Berbés, lugar tradicional de venta del pescado. Además, en Vigo se encuentra el Museo del Mar de Galicia, en el que se muestra la historia marítima de la región.

Por último, desde la empresa BLUSCUS Turismo Marinero, que ofrece actividades de pesca-turismo por la ría de Arousa (A Coruña) y de marisqueo con una posterior degustación gastronómica de productos del mar acompañada de los buenos vinos de la zona, englobados en famosa Denominación de Origen "Rías Baixas".

\subsection{Cataluña}

A lo largo de la costa catalana se ofertan diversas iniciativas de turismo marinero que engloban actividades variadas como la pesca-turismo, las degustaciones gastronómicas 
o las rutas por las instalaciones portuarias. En el año 2001 se construye en Palamós (Girona) el Museo de la Pesca, dado el interés por recuperar la identidad pesquera local (Alegret, 2003). Al amparo de esta infraestructura, se crea el Centro de Documentación de la Pesca y el Mar (DOCUMARE), un centro de información y documentación público especializado en el campo marítimo, pesquero y del consumo de pescado, que ofrece asesoramiento, apoyo técnico y documental a iniciativas y proyectos de investigación y divulgación destinados a conocer, difundir y poner en valor el litoral y la actividad de sus gentes dedicadas a la actividad pesquera. Posteriormente, se ha creado el Espai del Peix o Espacio del Pescado, ubicado en pleno puerto pesquero de la localidad, con el objetivo de contribuir al desarrollo del conocimiento, insistir en el papel de la sostenibilidad y seguir dando a conocer la variedad gastronomía de los productos del mar. En este sentido, entre el Ayuntamiento de Palamós y el Museo de la Pesca ofertan una amplia gama de actividades como la pesca-turismo en barcos de arrastre y artes menores, los show cooking (cocinar enfrente de los comensales) aprovechando el Espai del Peix, talleres de nudos marineros o visitas a la subasta del pescado.

En la localidad de Roses (Girona) se ha implantado a través del Ayuntamiento, la Cofradía de Pescadores y la Estación Náutica, el proyecto Roses Vila Marinera. Los tres actores implicados en esta iniciativa han sumado sus esfuerzos para impulsar la construcción del Centro de Turismo Pesquero, lugar que muestra las singularidades de la pesca tradicional a la sociedad en general y a los turistas en particular, creando unas sinergias muy beneficiosas para la localidad. En este caso se ofertan actividades de pesca-turismo en barcos de artes menores y de arrastre, la observación de la faena pesquera en un barco de recreo o a través de un kayak, modalidad que supone una mezcla entre el turismo de aventura y el marinero.

En L’Escala (Girona), la Cofradía de Pescadores ha construido el Centro de Interpretación del Pescado (MARAM) con el objetivo de fomentar la cultura del pescado, dar a conocer el trabajo y la vida del pescador y fomentar la pesca responsable. En este sentido, se ofertan actividades variadas de pesca-turismo en barcos de artes menores, visita a las instalaciones portuarias, incluyendo la subasta del pescado, pudiendo ser ésta teatralizada (se oferta para grupos escolares o adultos). Además, el MARAM cuenta con un espacio para la realización de jornadas y talleres gastronómicos.

Una de las iniciativas más originales de turismo marinero existentes en Cataluña se oferta en La Ametlla de Mar (Tarragona). La empresa atunera Balfegó ha puesto en marcha TUNA TOUR, con el fin de dar a conocer la historia del atún rojo y sus métodos de captura. En este sentido, se puede bucear entre los túnidos que se crían en cautividad en sus instalaciones. Esto se realiza mediante dos modalidades diferentes: una para personas que no poseen el título de buceo Open Water, que nadan en superficie y se sumergen a pulmón para ver los atunes, y la segunda para quienes posean la licencia mencionada anteriormente que pueden bucear hasta los 20 metros de profundidad. Además, esta empresa se ofrece la posibilidad de que grupos de escolares a partir de 5 años naden entre los atunes. Esta actividad tiene como fin que el alumnado pueda comprender la importancia de la sostenibilidad del medio natural. Por otro lado, la Cofradía de Pescadores y el Ayuntamiento han llegado a un acuerdo para ofertar la pesca-turismo en embarcaciones de arrastre y artes menores. 
Por último, la Organización de Armadores de Pesca de Cataluña (OPAC), oferta también la posibilidad de contemplar la faena de los pescadores, así como rutas guiadas por el puerto de Barcelona.

\subsection{Islas Baleares}

En las Islas Baleares se ha impulsado la pesca-turismo a partir de la aprobación del Decreto 22/2016, de 22 de abril, por el que se regulan las medidas para la diversificación de los sectores pesqueros y acuícola en las Islas Baleares. Las cofradías de pescadores de la isla de Mallorca ofertan la posibilidad de contemplar la faena a bordo de sus embarcaciones.

En cambio, no tenemos constancia de la realización de actividades de turismo marinero en tierra firme como la posibilidad de asistir a la subasta del pescado o visitar las instalaciones portuarias y otros elementos patrimoniales relacionados con el mundo de la pesca. No obstante, en noviembre de 2019 se ha aprobado la creación del Museo del Mar y de la Pesca en Ibiza a través de una iniciativa del Consejo Insular, el Gobierno Autonómico, el Ayuntamiento de Ibiza y la Autoridad Portuaria de Baleares.

\subsection{Comunidad Valenciana}

La Comunidad Valenciana ofrece diversas iniciativas de turismo marinero y de pescaturismo. La aprobación de la Ley 5/2017, de 10 de febrero, de pesca marítima y acuicultura de la Comunitat Valenciana, generados iniciativas de pesca-turismo.

La empresa Trip \& Feel ofrece la posibilidad de realizar esta actividad en los puertos de Peñíscola (Castellón), Jávea (Alicante), Vinarós (Castellón) y Castellón mediante embarcaciones de artes menores, cerco y arrastre.

Por otro lado, en Torrevieja (Alicante), se ha puesto en marcha Torrevieja Pesca Tradicional, que oferta la pesca-turismo en barcos de artes menores, concretamente los trasmalleros, y en los de cerco. Además, existe la posibilidad de ver cómo trabajan los pescadores desde una embarcación de recreo. Estas actividades acaban con una degustación gastronómica de productos marítimos.

Los pescadores de la Comunidad Valenciana se postulan a favor de transportar turistas en sus barcos (Herrera-Racionero et al., 2018), por lo que no se descarta que la oferta aumente en el futuro.

En Torrevieja también se ofertan dos itinerarios por las instalaciones portuarias. Uno de ellos está destinado a todas las edades en el que se da a conocer los diversos sistemas de pesca empleados en la faena pesquera, así como la técnica que emplean los pescadores para su reparación, se permite ver cómo se descarga el pescado y también la asistencia a la lonja de pescado para ver la subasta del mismo. El recorrido se complementa con una cata gastronómica de productos marineros. Otro recorrido se destina para grupos escolares en el que se realizan talleres de nudos marineros, reconocimientos de especies o papiroflexia, explicaciones de cómo se desarrolla la actividad pesquera y charlas con los pescadores del lugar.

Otras localidades como Calpe y El Campello (Alicante) y Peñíscola también han creado itinerarios turísticos por las instalaciones portuarias que se complementan con la 
asistencia a la subasta del pescado. Para ello, las lonjas de pescado han sido recientemente remodeladas con el fin de poder acoger a los turistas (observadores) en su interior.

En las tres provincias de la Comunidad Valenciana existen museos dedicados a la actividad pesquera, y todos los casos se les denomina Museo de la Mar. El de la provincia de Castellón se localiza en Peñíscola, y tiene como fin proteger, conservar y difundir el patrimonio cultural relacionado con la pesca. Como hecho singular destaca su sección dedicada a la evolución de los barcos, así como a las diversas artes de pesca empleados a lo largo de la historia. Además, este Museo cuenta con un espacio dedicado a la fauna marina y a los restos arqueológicos relacionados con el mar que han sido encontrados en la localidad.

El museo de Gandía (Valencia), contiene una exposición de réplicas a escala de numerosas embarcaciones históricas, desde buques de la armada española hasta embarcaciones tradicionales con las que los pescadores han faenado en aguas del Grao de la localidad.

En la provincia de Alicante se localizan dos museos, el de Santa Pola, que tienen como objetivo fundamental representar cómo era el modo de vida de los marineros a mediados del siglo XX, tanto a bordo de las embarcaciones como en su hogar. Por ello, se exponen detalles de artes de pesca tradicionales como el trasmallo, embarcaciones de pesca tradicional y la reproducción de una vivienda del pescador. El Museo del Mar y la Sal de Torrevieja, expone una selección de objetos que constituyen un reflejo de las raíces de la ciudad, como una muestra de artesanía salinera, colección de fotografías de época, maquetas de barcos, material arqueológico, elementos de pesca y navegación y otros.

\subsection{Andalucía}

Con una longitud de costa en torno a $800 \mathrm{~km}$ y con una tradición pesquera milenaria, en Andalucía el turismo marinero ha desarrollado poco. Destaca la creación del Club de Producto de Turismo Marinero de la Costa Occidental de Huelva. Su ámbito de actuación son los municipios de Ayamonte, Isla Cristina, Cartaya y Punta Umbría y su objetivo fundamental es poner en valor los recursos pesqueros para su difusión cultural y turística (Gómez, 2016). Esta iniciativa está ligada especialmente a las experiencias gastronómica, dada la calidad de los productos pesqueros de la zona. También se ofertan actividades como las visitas a las instalaciones portuarias.

En Tarifa (Cádiz), a través la empresa Nature Tarifa, se ofrece la posibilidad de contemplar la faena pesquera en la almadraba, en los momentos de la captura de los atunes de varios cientos de kilos por parte de los pescadores. También disponen para el alojamientos en villas rurales ubicadas en las proximidades de parques naturales, con el fin de ofertar un producto más completo.

Desde 2011 se ha impulsado en la Costa del Sol, concretamente en los puertos de Estepona (Figura 3), Caleta de Vélez y Fuengirola, el turismo marinero. En este sentido, se ofrecen rutas turísticas y gastronómicas, excursiones al mar para ver cómo trabajan los pescadores y talleres educativos de nudos marineros y preservación de entornos marítimos para escolares. 


\section{Figura 3 \\ EMPRESA DEDICADA A LA OFERTA DEL TURISMO MARINERO EN ESTEPONA. MÁLAGA}

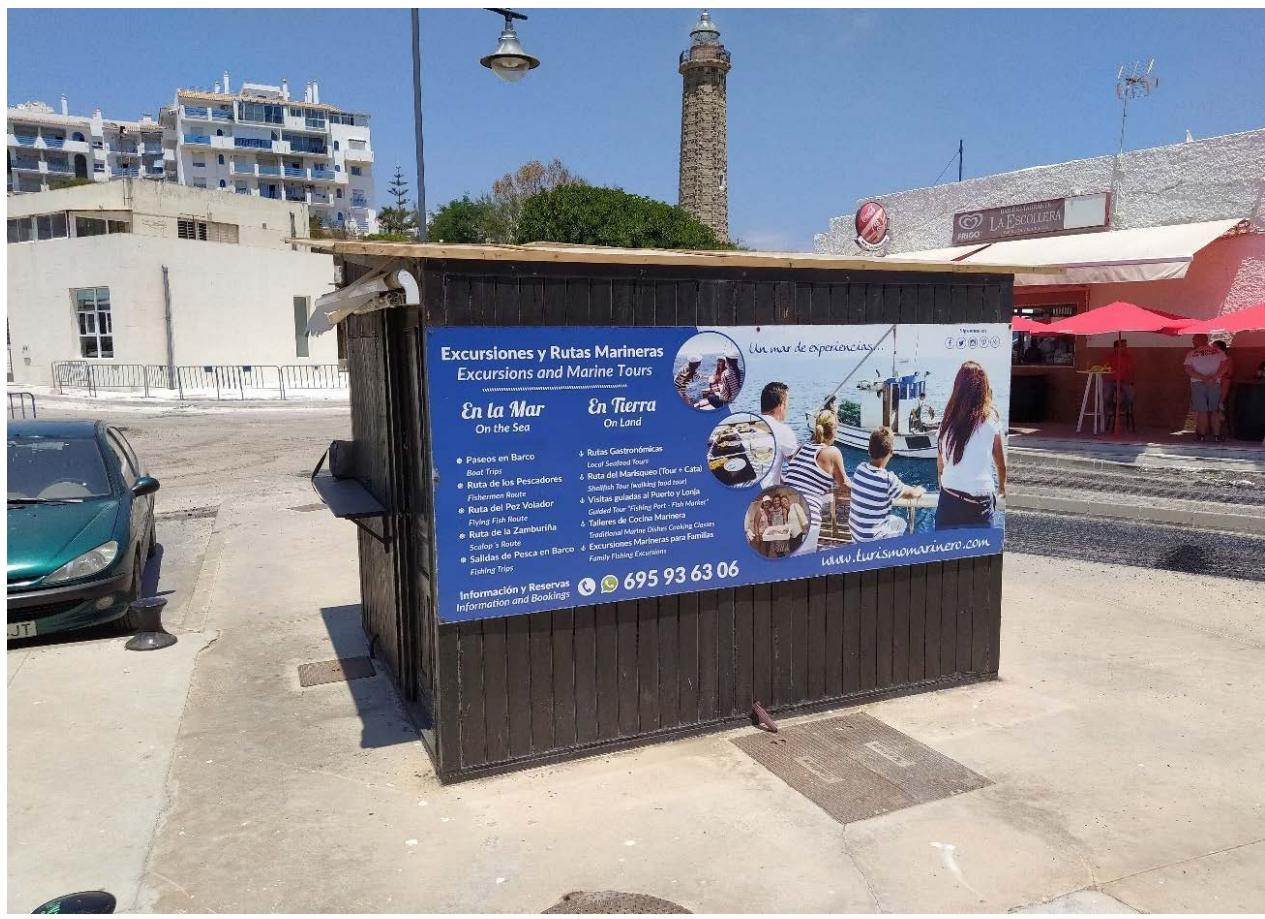

Fuente: Autor.

En Barbate (Cádiz) se ha construido un espacio museístico dedicado a la almadraba. Se trata de una puesta en valor de un arte de pesca ancestral que, tal y como indican García y Florido (2012), se emplea para capturar grandes especies pelágicas migratorias como albacoras y bonitos pero, sobre todo, el atún rojo. $\mathrm{Su}$ importancia radica en el legado sociocultural (costumbres, rituales, organización social, etc.) que ha surgido en torno a esta actividad productiva (Del Valle, 2018), así como en el paisaje que ha generado (Alcina y Amaya-Corchuelo, 2019).

En Adra (Almería) existe un Centro de Interpretación de la Pesca. Se trata de una instalación museística donde se da a conocer la vinculación histórica existente entre la localidad y el mar y la pesca. En dicho espacio el visitante puede conocer de primera mano el oficio de pescador, los distintos tipos de embarcaciones, los productos pesqueros o el modo de vida de las personas que trabajan en la pesca. Asimismo, desde su terraza se puede contemplar una visión panorámica del puerto pesquero de Adra. Además, el Centro está galardonado como "Centro Azul" por la Asociación de Educación Ambiental y del Consumidor (ADEAC) por su estímulo hacia los valores proambientales y de conservación de los ecosistemas naturales y de los entornos naturales que forman parte del patrimonio natural de Adra (Figura 4). 
Por último, algunas cofradías de pescadores de la provincia de Málaga organizan demostraciones del calado de un arte de pesca tradicional, como es la jábega. Con esta iniciativa se da a conocer cómo se faenaba hace décadas y se pone en valor como recurso turístico el sistema de pesca propiamente dicho.

\section{Figura 4}

\section{REPRODUCCIÓN DE EMBARCACIONES PESQUERAS EN EL CENTRO DE INTERPRETACIÓN DEL MAR. ADRA. ALMERÍA}

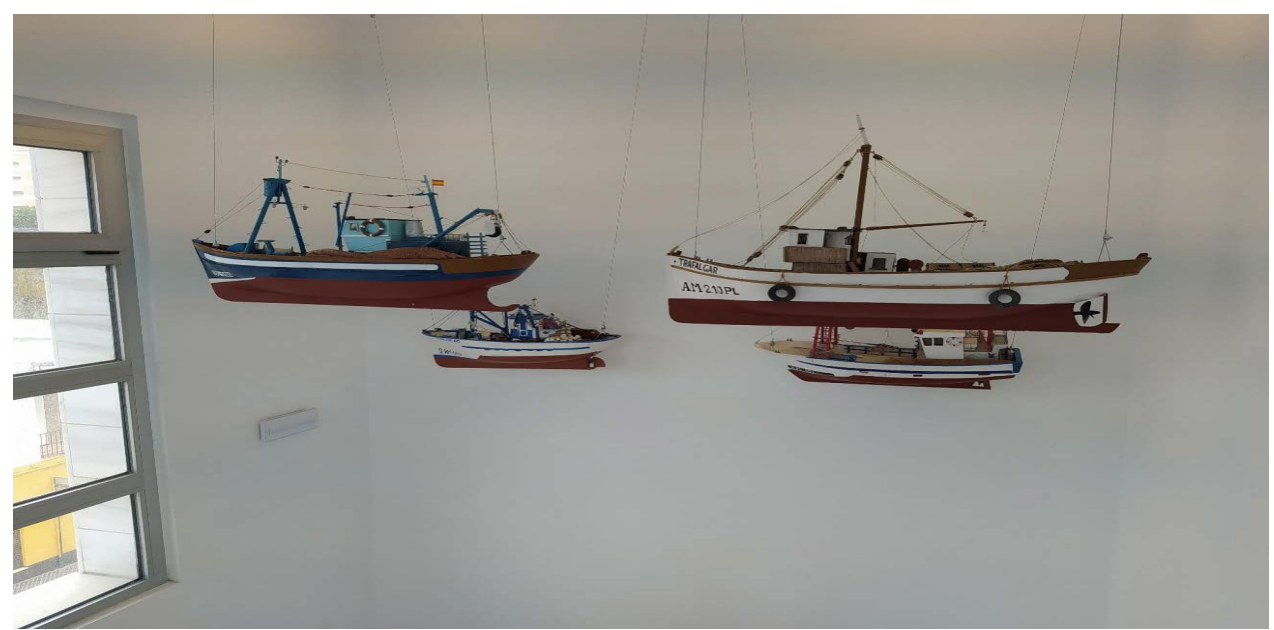

Fuente: Autor.

\subsection{Región de Murcia}

La implantación del turismo marinero en la Región de Murcia comienza el año 2004. Las 4 cofradías de pescadores (Águilas, Mazarrón, Cartagena y San Pedro del Pinatar) se adhirieron al proyecto europeo MARIMED: La pesca como factor de desarrollo del turismo sostenible. Sin embargo, este proyecto tan solo fue aprovechado en Águilas, donde se realizaron diversas acciones de remodelación del puerto pesquero y su entorno, así como la construcción del Centro de Interpretación del Mar (CIMAR). Esta infraestructura museística, primera por sus características en la Región de Murcia, cuenta con varios espacios visitables: se recrea la vivienda tradicional del pescador, una sala destinada a los artes y sistemas de pesca empleados en la localidad, varios acuarios con especies marinas de los 5 continentes, una exposición malacológica y una embarcación de arrastre que forma parte de la estructura arquitectura del CIMAR.

Águilas en 2009, basándose en el turismo marinero, participa en un nuevo Plan de Competitividad Turística denominado "El Mar y la Pesca", cuyo objetivo fundamental es la creación de un nuevo producto turístico, basado en la pesca tradicional y la cultura marinera local. Para que otorgue singularidad y diferenciación a la localidad respecto a otros destinos, y de esta forma permita aumentar la competitividad específica dentro del 
nuevo escenario turístico, además de que pueda suponer una opción desestacionalizadora real, a la vez que diversifique y complemente la oferta genérica de turismo de sol y playa (Pérez y Espejo, 2012).

En 2011 los vecinos del El Portús (Cartagena) inician la recreación de la jábega, con el fin de que este arte de pesca no quede en el olvido y los turistas puedan conocer cómo se faenaba hace más de medio siglo (Figura 5). La actividad se acompaña con una moraga (asado al aire libre de pescado) tradicional a orillas de la playa. Su éxito ha sido evidente, pues se celebra cada año el último sábado de agosto desde 2011.

\section{Figura 5 \\ RECREACIÓN DE LA JÁBEGA EN EL PORTÚS. CARTAGENA. REGIÓN DE MURCIA}

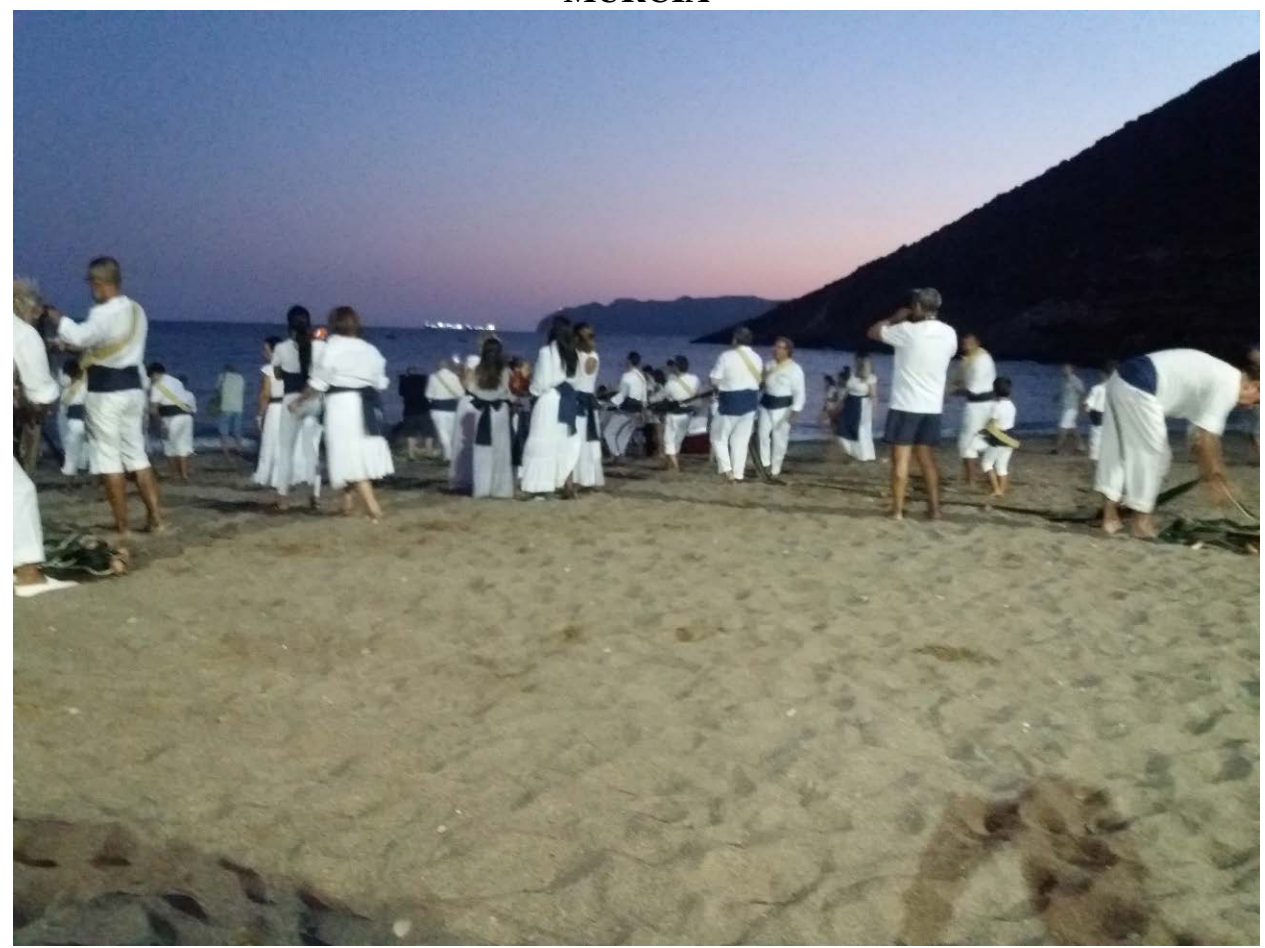

Fuente: Autor.

Por otro lado, dado el disposición del Gobierno de la Región de Murcia de ligar gastronomía y turismo, en los últimos años se han celebrado eventos con el fin de revalorizar la cocina local basada en productos del mar. Las Jornadas del Atún Rojo celebradas en Mazarrón en 2014 fueron las pioneras. Sin embargo, destacan por su continuidad en el tiempo, ya que se realizan ininterrumpidamente desde el año 2015, las Jornadas Gastronómicas de la Gamba Roja de Águilas, cuyo objetivo es promocionar el producto culinario más cotizado de la localidad. Además, desde 2017 se organiza en San Javier el evento Mi Mar 
Menor de Salazón, que consiste en continuar dando a conocer los productos pesqueros mediante talleres de cocina, show cooking, el ronqueo del atún así como las degustaciones gastronómicas (Moreno, 2019).

Otra de las iniciativas llevadas a cabo en materia de turismo pesquero es la oferta de visitas turísticas a infraestructuras relacionados con la pesca. Por ejemplo, se han organizado dos jornadas de puertas abiertas (noviembre de 2018 y abril de 2019) para visitar el faro de Cabo de Palos, el de mayor importancia y altura de cuantos se localizan en la Región de Murcia. En este sentido, y dado el éxito de las jornadas, la Autoridad Portuaria de Cartagena permite desde el verano de 2019 que este elemento patrimonial puede ser visitado por los turistas. Asimismo, localidades como Mazarrón y Águilas han remodelado sus lonjas pesqueras para hacerlas visitables durante la celebración de la subasta del pescado o como complemento de itinerarios por las instalaciones portuarias.

Por último, en San Pedro del Pinatar a través de la iniciativa Turismo Marinero Murcia se ofrece la posibilidad de realizar la pesca-turismo a bordo de embarcaciones de artes menores que faenan en el Mar Menor con artes tradicionales como el trasmallo o la charamita.

\subsection{Asturias}

En Asturias se ofertan recursos para el turismo marinero en las localidades de Luanco, Llanes, Avilés y Puerto de la Vega. En la primera de ellas se localiza el Museo Marítimo de Asturias (Figura 6), destinado a la conservación, estudio y exposición de todo tipo de materiales y documentos relacionados con la actividad marítima. Además, en las inmediaciones del puerto pesquero se han instalado panales expositivos de metacrilato que de forma didáctica informan al viajero sobre la historia de la actividad pesquera (Figura 7). Por otro lado, en Llanes existe la posibilidad de realizar un itinerario en el que se muestran los principales lugares de interés relacionados con la pesca (faro, puerto pesquero, lonja y paseos marítimos), así como visitar el Aula del Mar, que cuenta con objetos donados por la población local sobre pesca, la industria conservera y la emigración a América (Feo, 2010). Mientras que en Avilés y Puerto de la Vega se han remodelado sus lonjas pesqueras con el fin de que los turistas y los escolares puedan asistir a la subasta del pescado, tras realizar un itinerario por las instalaciones portuarias. 
Figura 6

MUSEO MARÍTIMO DE ASTURIAS. LUANCO

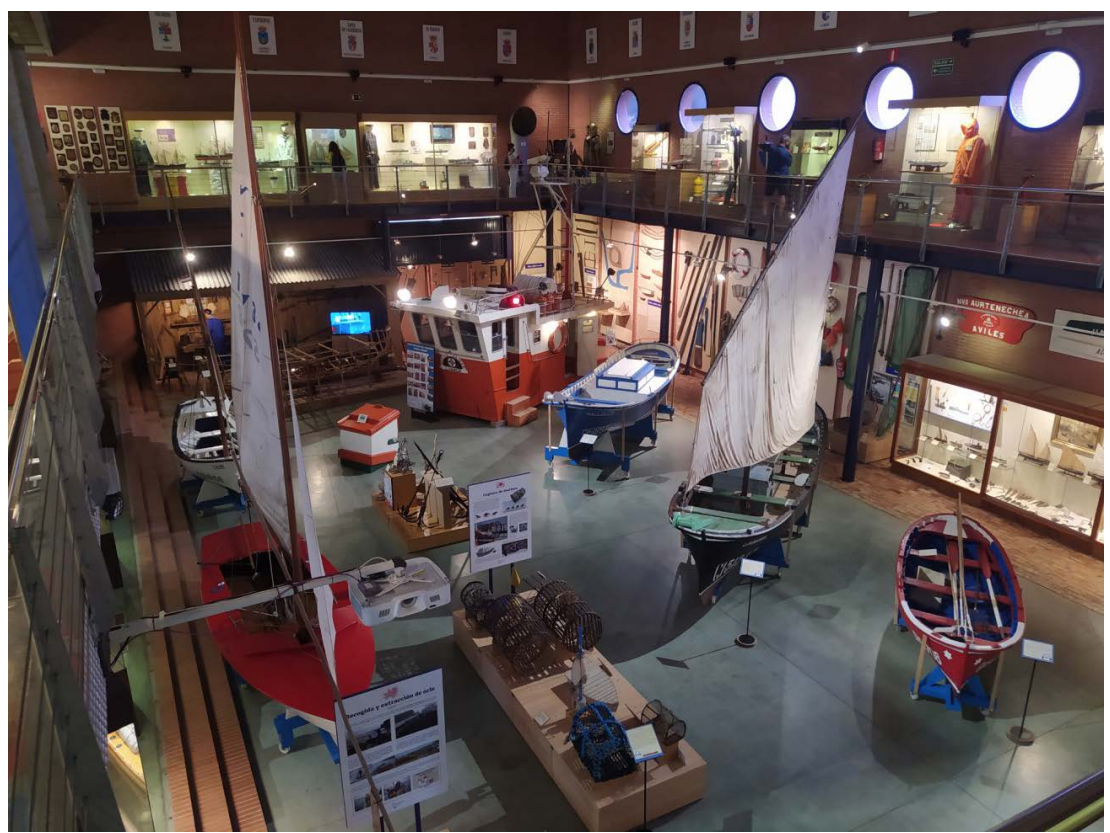

Fuente: Autor.

Figura 7

PANEL CON IMÁGENES DE LA RELACIÓN DE LA MUJER Y EL MAR. PUERTO PESQUERO DE LUANCO. ASTURIAS

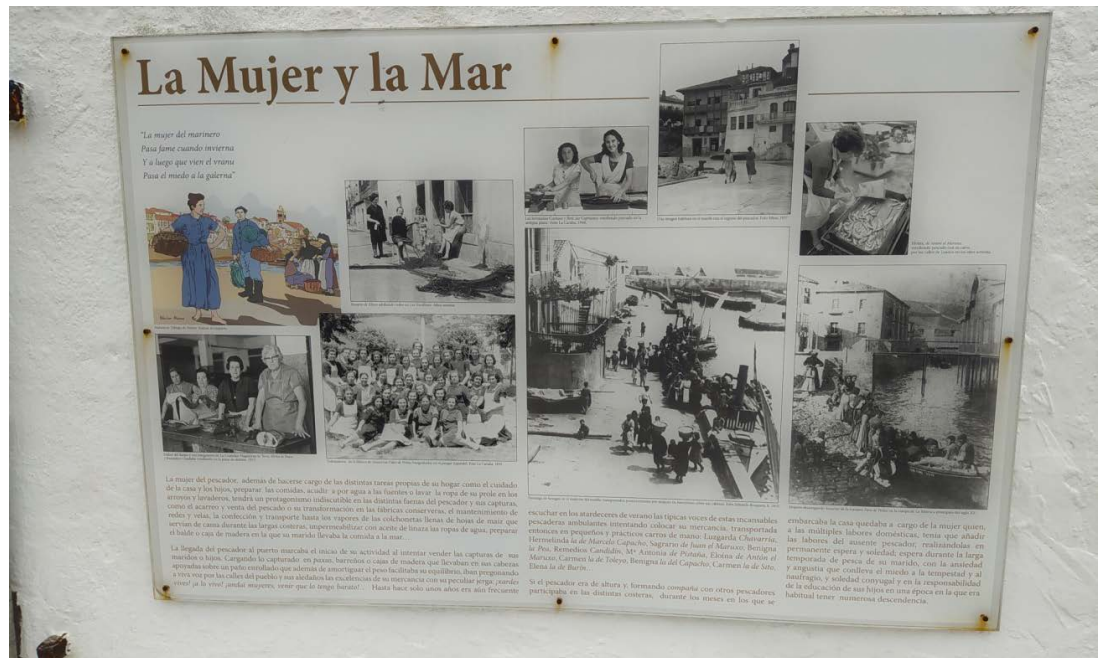

Fuente: Autor. 


\subsection{País Vasco}

En el País Vasco las infraestructuras para el turismo marinero se limita a una instalación museística, concretamente al Museo Naval de Guipúzcoa. Destinado a contribuir a la conservación, estudio y divulgación del patrimonio marítimo vasco, en él se exponen numerosos objetos relacionados con la actividad pesquera tradicional como anclas, artes de pesca, mapas o recreaciones de embarcaciones, por citar algunos ejemplos.

\subsection{Cantabria}

En Santander se localiza el Museo Marítimo del Cantábrico, lugar en el que se pone de manifiesto la importancia que la pesca ha tenido para esta región y todo lo que entraña el modo de vida de los pescadores y las rederas, desde los artes y sistemas empleados para el desempeño de la faena hasta sus ritos y creencias.

San Vicente de la Barquera, Santoña y Laredo son partícipes de un proyecto interregional, denominado Villas Marineras, conformado también por municipios de Galicia (Baiona, Sanxenxo, Ortigueira y Viveiro) y Asturias (Cudillero, Ribadesella y Llanes). El objetivo fundamental de esta iniciativa es dar a conocer el sector pesquero y la cultura marítima de estas localidades. Para ello, se realizan actividades diversas como la asistencia a la subasta del pescado, itinerarios por las instalaciones portuarias, talleres de fileteado de la anchoa o la visita a las rederas, con el fin de valorizar el trabajo de las mujeres ligado a la pesca.

\subsection{Islas Canarias}

En el archipiélago canario el turismo marinero apenas ha tenido implantación. No obstante, es preciso señalar la existencia de varios museos. En la isla de Fuerteventura se encuentra el Museo de Pesca Tradicional, concretamente en el Faro de El Tostón, en el que se exponen distintas artes pesqueras empleados en la localidad. Por otro lado, en Santiago del Teide y en Puerto de la Cruz (Tenerife), existen dos museos donde se recopilan maquetas de barcos, objetos pesqueros, la historia de la pesca local, así como fotografías del pasado marinero de la zona. Además, en ambos municipios se han realizado degustaciones gastronómicas con productos pesqueros, que destacan por su singularidad.

Como se ha constatado en esta relación por Comunidades Autónomas, las iniciativas tienen en común el objetivo de promocionar y valorizar la cultura de la pesca, así como intentar conseguir a través de la pesca-turismo rentas complementarias para los armadores de las embarcaciones. Una vez abordado el turismo marinero en las distintas Comunidades Autónomas españolas, se sintetizan en la Tabla 1 las actividades relativas a esta modalidad turística que pueden realizarse en cada una de ellas. 
Tabla 1

ACTIVIDADES DE TURISMO MARINERO OFERTADAS EN LAS COMUNIDADES AUTÓNOMAS ESPAÑOLAS

\begin{tabular}{|c|c|c|c|c|c|c|c|c|c|c|}
\hline & $\frac{\frac{\pi}{0}}{\frac{\pi}{0}}$ & 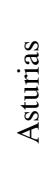 & 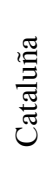 & $\begin{array}{l}\frac{\tilde{J}}{\tilde{J}} \\
\frac{\tilde{J}}{\tilde{d}} \\
\frac{\tilde{J}}{\tilde{\pi}} \\
\dot{\nu}\end{array}$ & $\begin{array}{l}\frac{\pi}{\tilde{U}} \\
\frac{0}{\pi} \\
0\end{array}$ & 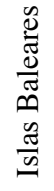 & 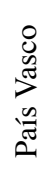 & 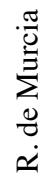 & 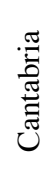 & 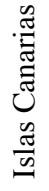 \\
\hline Pesca-turismo & $\mathrm{X}$ & & $\mathrm{X}$ & $\mathrm{X}$ & $\mathrm{X}$ & $\mathrm{X}$ & & $\mathrm{X}$ & & \\
\hline Taller de nudos & $\mathrm{X}$ & & $\mathrm{X}$ & & $\mathrm{X}$ & & & & & \\
\hline Museos & $X$ & $\mathrm{X}$ & $\mathrm{X}$ & $\mathrm{X}$ & $\mathrm{X}$ & & $\mathrm{X}$ & $\mathrm{X}$ & $\mathrm{X}$ & $\mathrm{X}$ \\
\hline Asistencia a la subasta del pescado & $\mathrm{X}$ & $\mathrm{X}$ & $\mathrm{X}$ & $\mathrm{X}$ & $\mathrm{X}$ & & & $\mathrm{X}$ & $\mathrm{X}$ & \\
\hline Itinerarios turísticos & $\mathrm{X}$ & $\mathrm{X}$ & $\mathrm{X}$ & $\mathrm{X}$ & $\mathrm{X}$ & & & $\mathrm{X}$ & $\mathrm{X}$ & \\
\hline Degustaciones gastronómicas & $X$ & & $X$ & $X$ & $X$ & & & $\mathrm{X}$ & $\mathrm{X}$ & $\mathrm{X}$ \\
\hline Actividades para escolares & $\mathrm{X}$ & & $\mathrm{X}$ & & $\mathrm{X}$ & & & & $\mathrm{X}$ & \\
\hline Recreación artes de pesca & $\mathrm{X}$ & & & & & & & $\mathrm{X}$ & & \\
\hline
\end{tabular}

Fuente: Elaboración propia.

\section{CONCLUSIONES}

El turismo marinero es una actividad reciente en España, ya que supera poco más de una década si se tiene en cuenta la creación de espacios museísticos sobre la actividad pesquera. Se ha constatado la presencia de esta modalidad turística en casi la totalidad de las Comunidades Autónomas litorales españolas, salvo las Islas Canarias. El número de iniciativas está en continua progresión, lo que demuestra que existe una predisposición por parte de los actores implicados (Administraciones públicas, cofradías de pescadores, armadores y empresas privadas) en poner en valor como recurso turístico la cultura marinera. Es decir, se ofrece un producto turístico complementario y alternativo al turismo de sol y playa propio de las zonas costeras.

Respecto al marco legislativo, se han constatado diferencias entre las Comunidades Autónomas que ofrecen la posibilidad de realizar la pesca-turismo. Por ejemplo, las leyes de Galicia y de la Comunidad Valenciana, no recogen la regulación en materia de seguridad a bordo de las embarcaciones, número de pasajeros o seguros de responsabilidad civil. Sin embargo, en los casos de Cataluña e Islas Baleares, elaboradas de una forma más exhaustiva, estos vacíos legales quedan totalmente subsanados. Conviene mencionar que la aprobación, por parte del Gobierno de España, del Real Decreto 239/2019, de 5 de abril, por el que se establecen las condiciones para el desarrollo de la actividad de pesca-turismo, es fundamental para dar el impulso definitivo al turismo marinero, ya que 
permitirá desarrollar la pesca-turismo en aquellas regiones donde no se ofertaba por la carencia de una legislación que lo amparase.

En lo que concierne a la implantación del turismo marinero, los contrastes regionales son evidentes. Galicia es el territorio donde más se ha desarrollado esta modalidad turística, dado que fue la primera en promoverlo a través de diversos proyectos de desarrollo local. No obstante, en los últimos años se ha impulsado con cierta fuerza en otros territorios como Cataluña o Andalucía. Entre las actividades que más se ofertan destacan las rutas guiadas que permiten conocer elementos patrimoniales ligados a la pesca y la asistencia a las lonjas para ver la subasta del pescado, presentes en la mayoría de las Comunidades Autónomas. Las degustaciones de productos del mar también están teniendo mucho éxito, y en bastantes casos implica la recuperación de tradiciones alimentarias y la difusión de la gastronomía local. Éstas se han consolidado en muchas localidades españolas, lo que muestra que existe un interés de la población en este tipo de iniciativas. Además, es necesario mencionar el incremento de los museos o centros de interpretación sobre la pesca, ya que se intenta salvaguardar el patrimonio cultural pesquero, material e inmaterial, conformado a lo largo de la historia y que ha dejado una gran huella en las zonas costeras. Por otro lado, la pesca-turismo solo se desarrolla en seis Comunidades Autónomas: Andalucía, Galicia, Cataluña, Comunidad Valenciana, Islas Baleares y la Región de Murcia, ya que hasta la fecha la carencia de un marco legal en el resto ha frenado su implantación en el resto de las regiones costeras españolas. El citado Real Decreto, aprobado en abril de 2019, aporta la normativa necesaria para que esta actividad turística basada en el sector pesquero continúe con su desarrollo, y de ese modo se puedan beneficia armadores, cofradías de pescadores y los sectores hosteleros y hoteleros se ven beneficiados por la misma.

En definitiva, el turismo marinero se está consolidando en los últimos años en España como un complemento y/o alternativa al turismo tradicional de sol y playa propio de las zonas litorales, aprovechando las sinergias ya consolidadas del mismo. Desde las Administraciones Públicas, cofradías de pescadores, armadores e iniciativas privadas se ha tratado de poner en valor para su aprovechamiento turístico elementos patrimoniales, tangibles e intangibles, vinculados al mundo de la pesca, que en gran medida son desconocidos para buena parte de la sociedad. Por último, a pesar de que no se está desarrollando con la misma intensidad en todas las Comunidades Autónomas, el número de iniciativas sigue aumentando, hecho inequívoco de que esta modalidad turística tiene presente y futuro, y entre sus objetivos fundamentales está la búsqueda de un desarrollo sostenible tanto del sector pesquero como del territorio donde se practica.

Declaración responsable: El autor declara que no existe ningún conflicto de interés relacionado con la publicación de este artículo.

\section{BIBLIOGRAFÍA}

ALCINA, J. y AMAYA-CORCHUELO, S. (2019): «El Paisaje almadrabero y el ejemplo de la costa de Cádiz. Aproximación desde una perspectiva patrimonialista», PASOS. Revista de Turismo y Patrimonio Cultural, vol. 117 (2), pp. 409-423. 
ALEGRET, J.L. (2003): El Port de Palamós. Memòria d'un centenari 1902-2002 . Barcelona, Generalitat de Catalunya.

ALEGRET, J.L. (2013): «Del patrimonio natural de los peces a patrimonio cultural del pescado: El Espai del Peix de Palamós», Revista Andaluza de Antropología, no 4, pp. 33-54.

BALLESTEROS, M.A., CHAPELA, R., DOMÍNGUEZ, J.M., FÉLIX, J. y JIMÉNEZ, M. (2012): «El turismo marinero, nuevas actividades de diversificación para las comunidades costeras en Andalucía y Galicia», en Chica, J.A., García, J., García, J. y Pérez, M.L. (Eds.) Actas del I Congreso Iberoamericano de Gestión Integrada de Áreas Litorales. Cádiz, Universidad de Cádiz, pp. 132-141.

BENUR, A. y BRAMWELL, B. (2015): «Tourism product development and product diversification in destinations», Tourism Management, vol.50, pp. 213-224.

BUTLER, R.W. (1980): «The concept of a tourist area cycle of evolution: Implications for management of resources». The Canadian Geographer, vol. XXIV (1), pp. 5-12.

CAAMAÑO, I., ANDRADE, M. y PÉREZ-GARCÍA, A. (2020): «El turismo marinero como opción de desarrollo local sostenible a partir del empoderamiento femenino». Cuadernos de Turismo, $\mathrm{n}^{\circ}$ 46, pp. 459-487.

CAAMAÑO-FRANCO, I., PÉREZ-GARCÍA, A. y ANDRADE-SUÁREZ, M. (2021): «Female entrepreneurship and marine tourism: Innovative practices on the coastline, en Rodrigues, J. (Ed.) Innovation and entrepreneurial opportunities in community tourism. IGI Global, pp. 172-190.

CHEN, C.L. y CHANG, Y.C. (2017):«A transition beyond traditional fisheries: Taiwan's experience with developing fishing tourism», Marine Policy, vol. 79, pp. 84-91.

CHEONG, S.M. (2003): «Privatizing tendencies: fishing communities and tourism in Korea», Marine Policy, vol. 27(1), pp. 23-29.

CARBONELL, E. (2014): «Les tradicions mariners com a patrimoni inmaterial», Revista d'Etnologia de Catalunya, no 39, pp. 116-121.

CILlari, T., FALAUTANO, M., CASTRIOTA, L., MARINO, V., VIVONA, P., y ANDALORO, F. (2012): «The use of bottom longline on soft bottoms: An opportunity of development for fishing tourism along a coastal area of the Strait of Sicily (Mediterranean Sea)», Ocean \& Coastal Management, vol. 55, pp. 20-26.

COLL, M.À. y SEGUÍ, M. (2014): «El papel del clima en la estacionalidad turística y la configuración de productos turísticos emergentes. El caso de Mallorca», Cuadernos de Turismo, $\mathrm{n}^{\mathrm{o}} 33$, pp. 15-30.

DECRETO 87/2012, de 31 de julio, sobre la pesca-turismo, el turismo pesquero y acuícola y las demostraciones de pesca en aguas marítimas y continentales de Cataluña. Diari Oficial de la Generalitat de Catalunya, nº 6.184, de 2 de agosto de 2012.

DECRETO 22/2016, de 22 de abril, por el que se regulan las medidas para la diversificación de los sectores pesquero y acuícola en las Islas Baleares. Boletín Oficial de las Islas Baleares, $\mathrm{n}^{\circ} 51$, de 23 de abril de 2016.

DEL VALLE, L. (2018): «Estudio para una gestión sostenible del patrimonio marítimopesquero: El caso del Real de la Almadraba de Nueva Umbría», en Moreno-Andrés,J., Bolado-Penagos, M., Sánchez-García, F., Jérez-Cepa, I., Simón-Díaz, M., Pérez- 
Miguel, M., Garrido, C. y González-Gordillo, J.I. (Eds.) Libro de Actas del I Congreso de Jóvenes Investigadores del Mar. Cádiz, Universidad de Cádiz, pp. 231-234.

DE LA CRUZ, R., VENDRALL, B., y PASCUAL, J.J. (2012): «¿Un mar de oportunidades? Innovaciones turístico-pesqueras en espacios marinos protegidos». PASOS. Revista de Turismo y Patrimonio Cultural, vol. 10 (1), pp. 19-30.

FEO, F. (2010): «Turismo cultural: Museos en Asturias», Cuadernos de Turismo, $\mathrm{n}^{\circ} 27$, pp. 341-356.

GARCÍA, A. y ALBUQUERQUE, F.J. (2003): «El turismo cultural y el de sol y playa ¿sustitutivos o complementarios?», Cuadernos de Turismo, $\mathrm{n}^{\circ}$ 11, pp. 97-106.

GARCÍA, E. y FLORIDO, D. (2012): «Tipos, origen y desarrollo histórico de las almadrabas antiguas. Desde época romana hasta el imperio bizantino», en Bernal, D. (Ed.) Pescar con arte. Fenicios y romanos en el origen de los aparejos andaluces. Cádiz, Servicio de Publicaciones de la Universidad de Cádiz, pp. 231-251.

GONZÁLEZ, F. y ANTON, S. (2016): «La planificación territorial de áreas turísticas. Conceptos, tipos y enfoques», en Simancas, M. (Coord.) La planificación y gestión territorial del turismo. Madrid, Síntesis, pp. 25-49.

GRÀCIA, F. (2016): «El turisme pesquer», en Sánchez, J.L. (Ed.) La pesca a la Mediterrània. Alicante, Publicaciones de la Universidad de Alicante, pp. 123-126.

HALL, C.M. (2001): «Trends in ocean and coastal tourism: the end of the last frontier?», Ocean \& Coastal Management, vol. 44 (9), pp. 601-618.

HEITMANN, S. (2011): «Tourist behaviour and tourism motivation», en Robinson, P., Heitmann, S. y Dieke, P. (Eds.) Research themes for tourism. Oxford, CABI Publishing.

HERRERA-RACIONERO, P., MIRET-PASTOR, L. y LIZCANO, E. (2018): «Viajar con la tradición: los pescadores artesanales ante la pesca-turismo en la Comunidad Valenciana (España)», Cuadernos de Turismo, n 41, pp. 279-293.

HUETE, R. (2008): «Tendencias del turismo residencial: el caso del Mediterráneo español», El Periplo Sustentable, n 14 , pp. 65-87.

IVARS, J.A., RODRÍGUEZ, I. y VERA, J.F. (2013): «The evolution of mass tourism destinations: New approaches beyond deterministic models in Benidorm (Spain)», Tourism Management, vol. 34, pp. 184-195.

JIMÉNEZ, C. (2016): «Pesca, cultura y turismo», en Jiménez, C. y García, J.J. (Coords.) Cultura y Pesca, Actas de las I Jornadas de Patrimonio Cultural Pesquero. Huelva, Universidad de Huelva, pp. 17-34.

KAUPPILA, P. y KARJALAINEN, T.P. (2012): «A process model to assess the regional economic impacts of fishing tourism: A case of study in northern of Finland». Fisheries Research, vol. 127, pp. 88-97.

LEY 11/2008, de 3 de diciembre, de Pesca de Galicia. Boletín Oficial del Estado (BOE), $\mathrm{n}^{\mathrm{o}} 15$, de 17 de enero de 2009.

LEY 6/2009, de 11 de diciembre, de modificación de la Ley 11/2008, de 3 de diciembre, de Pesca de Galicia. Boletín Oficial del Estado (BOE), n 30, de 4 de febrero de 2010.

LEY 6/2013, de 7 de noviembre, de pesca marítima, marisqueo y acuicultura en las Islas Baleares, Boletín Oficial del Estado (BOE) n 290, de 4 de diciembre de 2013. 
LEY 33/2014, de 26 de diciembre, por la que se modifica la Ley 3/2001, de 26 de marzo, de Pesca Marítima del Estado. Boletín Oficial del Estado (BOE), $\mathrm{n}^{\circ} 313$, de 27 de diciembre de 2014.

LEY 5/2017, de 10 de febrero, de pesca marítima y acuicultura de la Comunitat Valenciana. Boletín Oficial del Estado (BOE), n ${ }^{\circ}$ 56, de 7 de marzo de 2017.

LOIS, R.C. (2001): «La pesca», en Gil, A. y Gómez, J. (Coords.) Geografía de España. Barcelona, Ariel, pp. 425-439.

LOIS, R.C. y PIÑEIRO, M.A. (2020): «Fishing tourism as an opportunity for sustainable rural development-The case of Galicia, Spain», Land, vol. 9 (11), p. 437.

MARTÍNEZ, C. y MORENO, D. (2013): «La pesca como recurso turístico en Mazarrón (Murcia)», Estudios Turísticos, n 196, pp. 113-134.

MARTÍNEZ, C. y MORENO, D. (2014): Turismo marinero en Mazarrón: experiencia y futuro. Mazarrón, Ayuntamiento de Mazarrón.

MOLINERO, F. (1993): «Lógica espacial del sistema productivo: el declive de las actividades agrarias y pesqueras», en Méndez, R. y Molinero, F. (Coords.) Geografía de España. Barcelona, Ariel, pp. 371-378.

MIRET-PASTOR, L., MUÑOZ, C., HERRERA-RACIONERO, P. y MARTÍNEZ, R. (2015): «Análisis regional del turismo pesquero en España», Revista de Análisis Turístico, $\mathrm{n}^{\circ} 20$, pp. 23-28.

MIRET-PASTOR, L., MOLINA-GARCÍA, A., GARCÍA-ARANDA, C. y HERRERARACIONERO, P. (2018): «Analysis of the fisheries diversification funds in Spain during the period 2007-2014», Marine Policy, vol. 93, pp. 150-158.

MIRET-PASTOR, L., MOLINA-GARCÍA, A., GARCÍA-ARANDA, C. y HERRERARACIONERO, P. (2020): «The connection between recreational fishing and the traditional fishing sector in the emerging area of marine tourism: challenges and opportunities for diversification with the European Fisheries Funds (EFF)». ICES Journal of Marine Science, vol. 77 (6), pp. 2.369-2.374.

MORENO, D. (2018): La actividad pesquera en la Bahía de Mazarrón y el turismo marinero como propuesta de desarrollo. Tesis Doctoral. Universidad de Murcia.

MORENO, D. (2018): «Aportación a los conceptos de turismo marinero/pesquero y pescaturismo», Cuadernos de Turismo, $\mathrm{n}^{\circ}$ 42, pp. 385-396.

MORENO, D. (2019): «Recursos para la implantación del turismo marinero en el Mar Menor (Región de Murcia, España)». ROTUR. Revista de Ocio y Turismo, vol. 13 (1), pp. 1-11.

MORENO, D., GARCÍA, R. y ESPEJO, C. (2016): «Propuesta de turismo marinero en Mazarrón a raíz del Proyecto MARIMED "La pesca como factor de desarrollo sostenible"», en Santos, X.M., Taboada, P. y López, L. (Eds.) Actas del X Congreso Internacional de Turismo Rural y Desarrollo Sostenible. Santiago de Compostela, Universidad de Santiago de Compostela, pp. 421-432.

PADÍN, C. y ABOY, S. (2010): «Nuevos productos turísticos: la apuesta por el turismo marinero en Galicia». Tékhne-Revista de Estudos Politécnicos, $\mathrm{n}^{\circ}$ 14, pp. 55-83.

PARDELLAS, X.X. y ESPEJO, C. (2013): «Turismo pesquero», en Solsona, J. y Pardellas, X.X. (Dirs.) La actividad turística española en 2012. Madrid, Editorial Universitaria Ramón Areces, pp. 433-440. 
PARDELLAS, X.X., PADÍN, C. y ABOY, S. (2011): «Turismo pesquero: experiencias en Europa y en España». Papeles de Economía Española, n 128, pp. 221-227.

PASCUAL, J.J. y SANTANA, A. (2003): «Pesca y turismo: conflictos, sinergias y usos múltiples en Canarias», PH: Boletín del Instituto Andaluz del Patrimonio Histórico, vol. 11 (44), pp. 86-97.

PATIÑO, C.A. (2016): «El turismo marinero: un producto diferenciador y emergente de la oferta turística del litoral gallego», en Santos, X.M., Taboada, P. y López, L. (Eds.) Actas del X Congreso Internacional de Turismo Rural y Desarrollo Sostenible. Santiago de Compostela, Universidad de Santiago de Compostela, pp. 401-410.

PÉREZ, P. y ESPEJO, C. (2012): «La pesca como factor de desarrollo del turismo sostenible. El caso de Águilas (Murcia)», Cuadernos de Turismo, n 30, pp. 267-284.

PORTER, B.A. y ORAMS, M.B. (2014): «Exploring tourism as a potential development strategy for an artisanal fishing community in the Philippines: The case of Barangay Victory in Bolinao», Tourism in Marine Environments, vol. 10 (1-2), pp. 49-70.

REAL DECRETO 239/2019, de 5 de abril, por el que se establecen las condiciones para el desarrollo de la actividad pesca-turismo. Boletín Oficial del Estado (BOE), n ${ }^{\circ}$ 92, de 17 de abril de 2019.

ROGELJA, N. y JANKO, A. (2017): «How authentic is fishing tourism in Slovenia?», en Rogelja, N. y Janko, A. (Eds.) Fish on the Move. Cham, Springer International Publishing, pp. 145-170.

ROSELLÓ, V.M. (1986): “La pesca”, en Terán, M. de, Solé, L. y Vilá, J. (Coords.) Geografía General de España. Barcelona, Ariel, pp. 339-359.

SALVÀ, P. (1987): La pesca. Geografía de España. Madrid, Síntesis.

SCHUHBAUER, A. y KOCH, V. (2013): «Assessment of recreational fishery in the Galapagos Marine Reserve: failures and opportunities», Fisheries Research, vol. 144, pp. 103-110.

SEBIT, J., WOLFF, M., BRECKWOLDT, A. y JIDDAWI, N. (2016): «Have the fishing communities of Zanzibar Island benefited from increasing tourism development?», Journal of Development and Agricultural Economics, vol. 8 (5), pp. 95-107.

TUDDENHAM, D.B. (2010): «Maritime cultural landscapes, maritimity and quasi objects», Journal of Maritime Archeology, vol. 5 (1), pp. 5-16.

VASCONCELOS, V., DE SOUSA, R. y SANTOS, A. (2014): «Artesanato local e atividade pesqueira na comunidade do Carnaubal (Luís Correira, Piauí-Brasil) como fatores para o desenvolvimento sustentável do turismo», TURyDES, vol. 7 (16).

VERA, J.F. y BAÑOS, C.J. (2016): «La dimensión territorial del turismo. Los objetos de la ordenación territorial de áreas turísticas: la definición del sistema turístico», en Simancas, M. (Coord.) La planificación y gestión territorial del turismo. Madrid, Síntesis, pp. 51-83.

WOODS-BALLARD, A.J., PARSONS, E.C.M., HUGHES, A.J., VELANDER, K.A., LADLE, R.J. y WARBURTON, C.A. (2003): «The sustainability of whale-watching in Scotland», Journal of Sustainable Tourism, vol. 11 (1), pp. 40-55. 